\title{
Atrial Fibrillation and Acute Myocardial Infarction - an Inflammation-mediated Association
}

\author{
Diana Opincariu, Iulia Monica Chițu \\ University of Medicine and Pharmacy, Tîrgu Mureș, Romania
}

\begin{abstract}
Atrial fibrillation (AF) is an increasingly widespread healthcare problem. AF can frequently present as a complication in acute coronary syndromes (ACS), especially in ST-elevation acute myocardial infarction (AMI), in which case it is the most frequent supraventricular rhythm disturbance with an estimated incidence of $6.8-21 \%$. The presence of AF in ACS heralds worse outcomes in comparison to subjects in sinus rhythm, and several studies have shown that in AMI patients, both new-onset and pre-existing AF are associated with a higher risk of major adverse cardiovascular and cerebrovascular events during hospitalization. The cause of newonset $\mathrm{AF}$ in $\mathrm{AMI}$ is multifactorial. Although still incompletely understood, the mechanisms involved in the development of AF in acute myocardial ischemic events include the neurohormonal activation of the sympathetic nervous system that accompanies the AMI, ischemic involvement of the atrial myocytes, ventricular dysfunction, and atrial overload. The identification of patients at risk for $\mathrm{AF}$ is of great significance as it may lead to prompt therapeutic interventions and closer follow-up, thus improving prognosis and decreasing cardiovascular and cerebrovascular events. The present manuscript aims to summarize the current research findings related to new-onset AF in AMI patients, as well as the predictors and prognostic impact of this comorbid association.
\end{abstract}

Keywords: atrial fibrillation, acute myocardial infarction, risk prediction

\section{ARTICLE HISTORY}

Received: August 19, 2018

Accepted: September 11, 2018

\section{CORRESPONDENCE}

\section{Diana Opincariu}

Str. Gheorghe Marinescu nr. 38

540139 Tîrgu Mureș, Romania

Tel: +40 265215551

E-mail: diana.opincariu@yahoo.ro

\section{INTRODUCTION}

Atrial fibrillation $(\mathrm{AF})$ is an increasingly widespread healthcare problem, with a reported incidence of 20.9 million cases in males and 12.6 million cases in the female population worldwide. ${ }^{1,2}$ The prevalence of this supraventricular arrhythmia is increasing with age, and it more often affects subjects with coronary artery disease, heart failure, hypertension, obesity, diabetes, or chronic renal disorders. ${ }^{3-5} \mathrm{AF}$ can also present as a complication in acute coronary syndromes (ACS), especially in ST-elevation myocardial infarction, in which case it is the most frequent supraventricular rhythm disturbance, with an estimated incidence of $6.8-21 \% .^{6-9}$ The combination of $\mathrm{AF}$ and acute myocardial infarction (AMI) is of particular interest, since the development of either disorder can negatively and substantially impact the prognosis of the other. The occurrence of AF in AMI patients can lead to rapid irregular ventricular rates, thus further impairing ventricular function and coronary perfusion, with enhanced myocardial ischemia, volume overload, and elevated filling pressures. ${ }^{8,9}$ The higher incidence of $\mathrm{AF}$ in AMI patients is influenced by pre-existing AF, left ventricular dysfunction, and hemodynamic disturbances with subsequent catecholamine release either as a response to low perfusion pressures, or iatrogenic due to use of ino- 
tropic or vasoactive agents. Other reported risk factors for $\mathrm{AF}$ include diabetes, metabolic syndrome, chronic renal failure, or extensive myocardial ischemia, which encompasses a large portion of the left ventricle as well as the atrial myocytes. ${ }^{8,10,11}$

The presence of AF in ACS heralds worse outcomes in comparison to subjects in sinus rhythm, since several studies have shown that both new-onset and pre-existing $\mathrm{AF}$ are significantly associated with the risk of major adverse cardiovascular and cerebrovascular events during hospitalization. ${ }^{12,13}$

In addition to the increased cardiovascular burden and impaired prognosis, the comorbid relation between AMI and $\mathrm{AF}$ also attracts higher healthcare costs. The estimated costs used in out-patient treatment, hospitalizations, and medical treatments for AF have been reported around 6.6 billion dollars annually, while the associated costs for a single acute coronary event have been estimated between 34,087-86,914 dollars in 2005, in the United States. The approximate costs increase by up to $40 \%$ if an ACS patient presents $\mathrm{AF}$ as a complication. ${ }^{14-16}$

The present manuscript aims to summarize the current research findings related to new-onset AF in AMI patients, as well as the predictors and prognostic impact of this comorbid association.

\section{ETIOLOGY AND CONSEQUENCES OF AF IN AMI}

The cause for new-onset AF in AMI subjects is multifactorial, various factors as well as a genetic dimension being reported. AF leads to the deterioration of coronary perfusion and ischemia, with a negative impact on patient outcomes. Although still incompletely understood, the mechanisms involved in the development of $\mathrm{AF}$ in acute myocardial ischemic events include the neurohormonal activation of the sympathetic nervous system that accompanies the AMI, ischemic involvement of the atrial myocytes, ventricular dysfunction, and atrial overload. ${ }^{17,18}$ In general, AF is triggered by focal automaticity and electrical re-entry in the area surrounding the pulmonary veins. Several factors have been reported to be associated with $\mathrm{AF}$ in AMI patients, such as hypertension, metabolic disorders, structural or valvular heart disease. The arrhythmia itself leads to a structural remodeling of the atria with subsequent fibrosis, adipose infiltration, inflammatory infiltrates, which will ultimately lead to the so-called "electrical remodeling" that is optimal for developing reentrant circuits within the atrial wall and perpetuation of the arrhytmia. ${ }^{19-21}$ The various physiopathological mechanisms in AF initiation and persistence include stretch- induced myocardial fibrosis, which may be caused by left ventricular overload, and dysfunction secondary to acute infarctions. In acute coronary events, AF can also result from a decreased contractility of the atrial myocardium, caused by involvement of the atrial branch of the coronary artery, by fatty infiltration or inflammation, or by calcium imbalance. ${ }^{22-25}$

\section{ATRIAL ISCHEMIA}

The ischemia of atrial myocytes as a trigger for new-onset AF has been suggested by a study that had experimentally induced atrial branch occlusions on animal models, leading to prolonged atrial conduction, increased electrical heterogeneity, and higher rates of induced atrial fibrillation episodes. These episodes had an increased likelihood to persist, compared to controls or to animals with left anterior descendant occlusions. ${ }^{26} \mathrm{~A}$ study on 149 patients with ACS, out of which $4.9 \%$ had developed AF during hospitalization, showed that although there were no differences regarding the cardiovascular risk profile and associated disease, patients with atrial branch atherosclerosis or ischemic involvement of the atrial vasculature were more expected to present supraventricular arrhythmia. ${ }^{27}$ These studies suggest that the arrhythmia is triggered by the compromised atrial coronary vasculature rather than neurohormonal activation.

\section{ATRIAL STRETCH AND NEUROHORMONAL ACTIVATION}

Increased stretch of the atrial wall is caused by various disorders that lead to increased volume overload either directly, as in atrioventricular valve regurgitation, or secondary to left ventricular increased pressures, in congestive heart failure, acute heart failure caused my myocardial ischemia, aortic valve disease, or structural cardiac diseases. The increased left ventricular pressure is transmitted to the left atrium, leading to neurohormonal activation, which has been implicated in fibrosis formation and cardiac remodeling via the renin-angiotensinaldosterone pathways. In addition, the increased left ventricular wall stress leads to overstimulation of the same neurohormonal system, consequent heart failure and atrial remodeling, both structurally and electrically. ${ }^{28-30}$ The acute myocardial ischemia, as well as the mitral regurgitation due to papillary ischemia, enhance the atrial overload and trigger AF with rapid ventricular response, which will, in turn, worsen the already altered coronary perfusion, decrease the cardiac output secondary to the loss of atrial contraction, and also impair the diastolic and 
systolic function of the left ventricle. The decreased cardiac output will further stimulate the sympathetic nervous system, with secondary adrenergic stimulation that leads to the creation of a vicious circle, with higher ventricular overload, more enhanced atrial stretch, and even more increased neurohormonal activation, ultimately leading to extension of the infarction and worse outcomes. ${ }^{31-34}$

\section{INFLAMMATORY RESPONSE AS A TRIGGER FOR AF IN THE POST-INFARCTION PERIOD}

Several studies have linked an increased inflammatory response with the development and persistence of $\mathrm{AF}^{35-38}$ The independent association between $\mathrm{AF}$ and the serum level of C-reactive protein (CRP), which is illustrative for an acute-phase inflammatory response, increases the likelihood of AMI patients to develop the supraventricular arrhytmia. ${ }^{39,40}$

Myocardial ischemia has been linked to increased inflammatory response. ${ }^{41-46}$ Acute myocardial ischemia leads to an intense inflammatory response which is of utmost importance for the process of cardiac repair. The exacerbation of this normal repair mechanism can lead to further promotion of myocardial damage and left ventricular remodeling, with subsequent development of heart failure following MI. ${ }^{47-49} \mathrm{C}$-reactive protein as a marker for sustained inflammation following an acute MI can be induced by myocardial ischemia and existing unstable coronary plaques and has been established as a novel predictor for cardiovascular disease, as well as a predictor for adverse outcomes in MI. ${ }^{50-53}$ Other inflammatory biomarkers that present elevated serum levels following an AMI include tumor necrosis factor alpha, interleukin-6, or macrophage migration inhibitory factor, which have also been linked to mortality rates and adverse events following an acute coronary syndrome. .4-56 $^{-56}$

Inflammation has also been incriminated in the development and persistence of AF. ${ }^{57,58}$ The first observation that led to the hypothesis that inflammation may have a role in the genesis of the supraventricular arrhythmia was its higher incidence in patients with clinical conditions that are associated with enhanced inflammatory response, such as pericarditis and myocarditis, or cardiac surgery.59 The contribution of the inflammatory process in $\mathrm{AF}$ has been proved by histological studies on atrial biopsies in patients with lone atrial fibrillation in which several inflammatory infiltrates were observed. ${ }^{60}$

Several studies have shown the connection between increased levels of pro-inflammatory biomarkers and $\mathrm{AF}$; however, there are still uncertainties whether the ar- rhythmia is caused by inflammation, or that the inflammation is a consequence of the arrhythmia. A study that included 5,806 subjects from the Cardiovascular Risk Study, with a mean follow-up period of $6.9 \pm 1.6$ years, showed that CRP was significantly associated with AF (fourth quartile - mean CRP levels $<3.41 \mathrm{mg} / \mathrm{L}$ vs. first quartile - mean CRP levels $<0.97 \mathrm{mg} / \mathrm{L}$, adjusted HR 1.31, 95\% CI 1.08 to 1.58, p = 0.005), and also, elevated CRP levels predicted the risk for future arrhythmia development (adjusted hazard ratio for 1-SD increase 1.24, 95\% CI 1.11 to $1.40, \mathrm{p}<0.001) .{ }^{61}$ Chung et al. have shown that higher levels of CRP were present in patients with permanent $\mathrm{AF}$ compared to paroxysmal AF, which could indicate that inflammation is related to the burden of AF. ${ }^{62}$ Alternatively, a study on 52 subjects with persistent $\mathrm{AF}$ (over 3 months) who underwent electrical conversion, showed that those with recurrence at 1 month presented significantly higher baseline high-sensitivity CRP (hs-CRP) levels compared to those who remained in sinus rhythm $(0.5 \pm 0.18 \mathrm{mg} / \mathrm{dL}$ vs. $0.29 \pm 0.13 \mathrm{mg} / \mathrm{dL}$, respectively, $\mathrm{p}<0.001)$. Also, there was a significant decrease in hs-CRP levels after sinus rhythm restoration $(0.29 \pm 0.13 \mathrm{mg} / \mathrm{dL}$ before vs. $0.10 \pm$ $0.06 \mathrm{mg} / \mathrm{dL}$ after, $\mathrm{p}<0.001)$, whereas patients with recurrence presented similar levels $(0.05 \pm 1.8 \mathrm{mg} / \mathrm{dL}$ before vs . $0.56 \pm 0.24 \mathrm{mg} / \mathrm{dL}$ after, $\mathrm{p}=0.42) .{ }^{63}$

In a study that analyzed 971 patients with significant coronary artery disease, several inflammatory cytokines, such as interleukin-6, as well as an increased left atrial diameter have been shown to correlate with the genesis and duration of AF. ${ }^{64}$ Elevated levels of TNF-alpha, interleukin-8, interleukin-10, and monocyte chemoattractant protein-1 (MCP-1) were found in a higher number of patients with persistent $\mathrm{AF}$ compared to paroxysmal $\mathrm{AF}$ and arrhythmic patients compared to sinus-rhythm controls. ${ }^{65-67}$

The enhanced inflammatory response expressed either locally or at a systemic level, ${ }^{68}$ seems to be also one of the factors intertwined in the thrombogenic milieu present in the atria of AF subjects, alongside endothelial dysfunction and platelet activation. ${ }^{35,59}$ A study has shown that increased serum interleukin- 6 was an independent predictor for stroke and death in a follow-up period of 6 years, ${ }^{69}$ while another research has linked high CRP values with the incidence of spontaneous echo contrast in the left atrial cavity and appendage. ${ }^{70}$

This bidirectional relationship, inflammation - arrhythmia - inflammation, in the sense that AF is triggered but also generates an inflammatory response, could be one of the explanations of the "AF begets AF" concept. Fast irregular atrial depolarizations lead to atrial fibrosis 


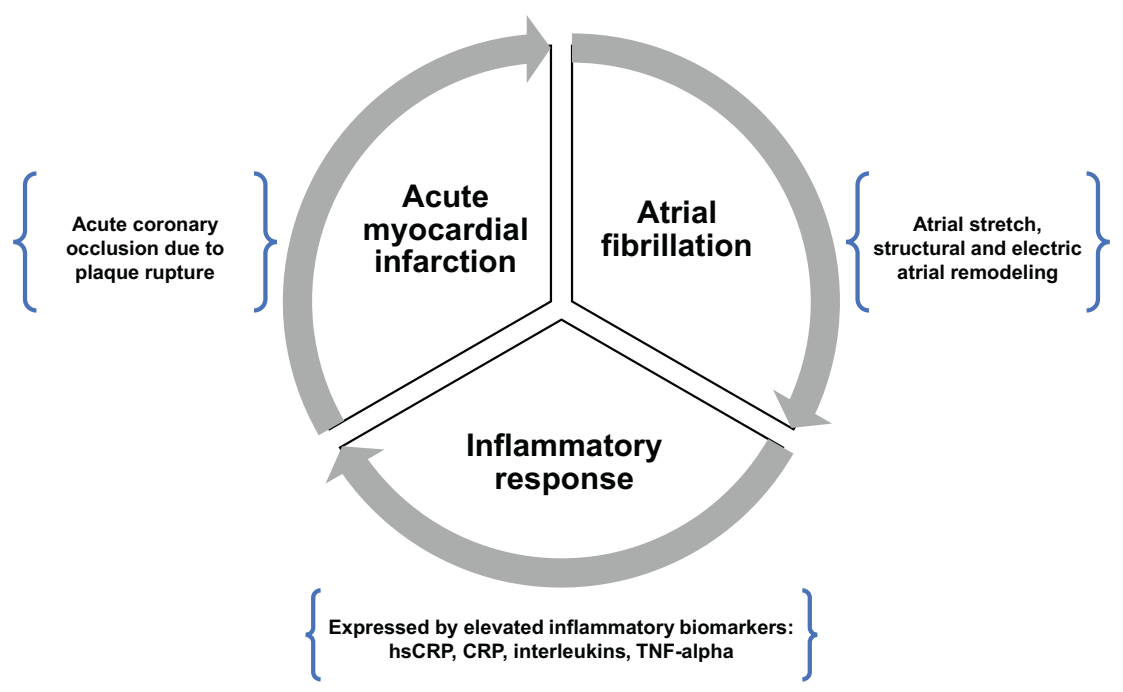

FIGURE 1. Inflammatory response in acute myocardial infarction triggers onset and persistence of atrial fibrillation, which will further enhance inflammation with subsequent atrial structural and electrical remodeling

and necrosis of myocardial fibers, which in turn generates a low inflammatory response with further structural and electrical atrial remodeling, a cycle that illustrates the impact of both inflammation and remodeling in the initiation, persistence, recurrence, and burden of AF.

The inflammatory response secondary to an AMI is not limited to the infarcted myocardium, but it is also present in the remote non-infarcted areas, which can explain how pro-inflammatory cytokine release can indorse $\mathrm{AF}$ in these patients (Figure 1). A study published in 2007, which included 1,209 patients admitted for AMI, showed that patients who had developed new-onset AF presented a positive and significant association with hsCRP measured at 12 and 24 hours from onset of symptoms, respectively ( $\mathrm{p}$ for trend $<0.001$ ). ${ }^{71}$ This was one of the first studies to demonstrate the impact of enhanced inflammatory response in the development of $\mathrm{AF}$ in the early post-infarction period. Another study conducted on 409 consecutive AMI patients showed similar results, that hs-CRP levels were significantly higher in patients with early AF (within $24 \mathrm{~h}$ from onset of the acute coronary event) compared to patients in sinus rhythm ( 14.5 $\mathrm{mg} / \mathrm{L}$ vs. $6.5 \mathrm{mg} / \mathrm{L}, \mathrm{p}=0.01$ ), and that there was a progressive increase in early-onset AF with increasing tertiles of hs-CRP (3.6\% in the first tertile, $8.9 \%$ in the second, and $14.1 \%$ in the third tertile, respectively, $\mathrm{p}=0.02$ ). However, their results were only applicable for patients without left atrial dilation, showing that hs-CRP levels as biomarkers for enhanced inflammatory response in the post-infarction period could contribute to the process of left atrial remodeling and dilation. ${ }^{22}$ A meta-analysis published in 2015, which included 6 studies and 4,153
AMI patients (363 with and 3,790 without new-onset $\mathrm{AF}$ ), aimed to evaluate the role of CRP levels in the occurrence of AF in AMI. Their results showed that elevated CRP levels are associated with a higher risk of new-onset $\mathrm{AF}$, but that $\mathrm{CRP}$ was not independently linked to the development of the arrhythmia, other potential risk factors including age, gender, time to revascularization, or infarct location. ${ }^{73}$

\section{AF AS A PROGNOSTIC FACTOR IN AMI}

AF occurring as a complication of acute myocardial ischemic events has been shown to negatively impact patient outcome and mortality rates, both during hospitalization and during the long-term follow-up. Despite its negative impact on outcomes, AF is not perceived by clinicians as a critical complication in the acute post-infarction period, in contrast to ventricular arrhythmias, acute heart failure, cardiogenic shock, or mechanical complications. However, $\mathrm{AF}$ is associated with a more than $40 \%$ increase in mortality compared to AMI subjects in sinus rhythm, as shown by a meta-analysis published by Jabre et al. (2011), on 43 studies including 278,854 patients. ${ }^{13}$ The study also showed that negative outcomes are persistently independent of the arrhythmia onset, while new-onset $\mathrm{AF}$ is significantly associated with higher death rates even after adjustments for age, diabetes, increased blood pressure, chronic congestive heart failure, previous myocardial infarction, or coronary revascularization, which have all been associated with increased mortality both in patients with AMI and chronic AF. ${ }^{13}$ New-onset AF in the context of acute myocardial isch- 
emia can lead to impaired patient outcomes due to its effect on the already unstable hemodynamic status via loss of atrial contraction and atrioventricular synchrony, and irregular rapid ventricular response with subsequent decrease in cardiac output. ${ }^{74}$ The irregular rapid ventricular response caused by AF may also trigger severe ventricular tachyarrhythmias due to irregular $\mathrm{R}-\mathrm{R}$ intervals, ischemia, or overactivation of the sympathetic nervous system. ${ }^{75,76}$ A prospective study on 600 patients in sinus rhythm on admission, with ST-elevation and non-ST elevation AMI (Vukmirovic et al., 2017), aimed to evaluate the prognostic role of new-onset AF, both during hospitalization as well as during a follow-up period of 84 months after discharge. Their results showed that the strongest predictors for new-onset AF included older age, increased left atrial diameter, moderate to severe mitral regurgitation, increased serum levels of brainnatriuretic peptide (BNP), and obesity. Also, the study revealed that subjects who had developed AF during hospital admission presented significantly higher mortality rates, both during hospital stay, as well as on the long term, compared to patients in sinus rhythm. ${ }^{77}$ Another meta-analysis published in 2012 (Angeli et al.), on 24 clinical studies that evaluated the prognostic role of $\mathrm{AF}$ in the early post-infarction period on all-cause mortality during hospitalization, revealed that $\mathrm{AF}$ occurring during AMI, irrespective of its onset, was significantly associated with all-cause death rates (OR 2.00, 95\% CI 1.93 to 2.08, p <0.0001), and that not only new-onset (OR 3.38, 95\% CI 2.98 to 3.83, p <0.0001), but also uncertain onset (OR 1.90, 95\% CI 1.83 to $1.98, \mathrm{p}<0.0001$ ) and permanent $\mathrm{AF}$ (OR 2.01, 95\% CI 1.70 to 2.38, p <0.0001) were linked to higher death rates. ${ }^{12}$ The Cooperative Cardiovascular Project (CCP), which included 106,780 elderly subjects aged over 65 years with AMI and AF of various onset types, showed that subjects with supraventricular arrhythmia had significantly worse outcomes compared to those in sinus rhythm, including during hospitalization (25.3\% vs. $16.0 \%, \mathrm{p}=0.001$, OR 1.77, 95\% CI 1.71 to 1.84 ), at 30 days (29.3\% vs. $19.1 \%, \mathrm{p}=0.001$, OR $1.76,95 \% \mathrm{CI}$ 1.71 to 1.82 ), and during the 1 -year follow-up ( $48.3 \%$ vs. $32.7 \%, \mathrm{p}=0.001, \mathrm{OR} 1.92,95 \% \mathrm{CI} 1.87$ to 1.98 ), even after adjustment for demographical, clinical, and therapeutic parameters. The same study revealed that $\mathrm{AF}$ was more frequently associated with reinfarction, cerebrovascular accidents, congestive heart failure, and admissions in the Intensive Care Unit (ICU), while the overall hospitalization period was significantly longer in arrhythmic subjects compared to sinus rhythm controls (9.6 days vs. 7.6 days, $\mathrm{p}<0.0001)^{9}{ }^{9}$

\section{PREDICTORS FOR AF IN AMI}

Given the associated risk of AF in AMI and its prognostic value in patients with ACS, it would be useful to identify patients at risk for the new onset of this supraventricular arrhythmia.

The Cooperative Cardiovascular Project was one of the largest patient cohorts $(106,780$ included subjects) that evaluated the clinical characteristics of patients with new-onset AF in the context of acute coronary events. Their results revealed that compared to patients in sinus rhythm, those in AF were significantly older (mean age 79.2 years vs. 76.8 years, $p<0.0001$ ), presented significantly higher heart rate on admission (95.8 bpm vs. 86.8 bpm, p <0.0001), more advanced heart failure (Killip class IV: $4 \%$ vs. $2 \%, p=0.001$ ), and higher frequency of previous MI (34.2\% vs. $32.3 \%, p=0.001)$ and revascularization. At the same time, multivariate analysis in this study showed that advanced acute heart failure with Killip class IV was the most important predictor of $\mathrm{AF}$ development (OR 1.58, 95\% CI 1.45 to 1.73). ${ }^{9}$ Another study conducted in 2017 showed that by logistic regression analysis, the most powerful predictors of AF during hospitalization for AMI were age over 70 years (OR 2.37, 95\% CI 1.23 to $4.58, \mathrm{p}=$ $0.010)$, obesity defined as a body mass index over $25 \mathrm{~kg} / \mathrm{m}^{2}$ (OR 1.17, 95\% CI 1.04 to 1.33, p = 0.012), significant mitral insufficiency (OR 3.56, 95\% CI 1.25 to $10.32, p=0.018$ ), and elevated levels of BNP (OR 2.12, 95\% CI 1.24 to 3.33, $\mathrm{p}=0.048)$. Also, patients with new-onset AF presented significantly lower left ventricular ejection fraction (41.7 \pm $4.6 \%$ vs. $43.9 \pm 4.9 \%, \mathrm{p}=0.003)$, larger left atrium diameter $(43.6 \pm 3.9 \mathrm{~mm}$ vs. $40.4 \pm 3.6 \mathrm{~mm}, \mathrm{p}<0.001)$, higher frequency of moderate to severe mitral regurgitation ( $25 \%$ vs. 7.3\%, p <0.001), higher heart rate upon admission ( 85.5 bpm vs. 77 bpm, p <0.001), and also a higher incidence of ventricular tachycardia during hospital stay (18.8\% vs. $7.6 \%, p=0.014) .77$ Vukmirovic et al. also analyzed levels of cardiac biomarkers in association with the risk of developing $\mathrm{AF}$ and showed that while hemoglobin levels and anemic patients were not significantly different between $\mathrm{AF}$ and non-AF patients, there was a significantly higher number of $\mathrm{AF}$ cases that developed contrast-induced nephropathy ( $37.5 \%$ vs. $15.0 \% \mathrm{p}<0.001$ ). AF patients also presented significantly higher levels of BNP as an illustrator of neurohormonal activation (272 vs. $64.5, \mathrm{p}<0.001$ ), and higher levels of hs-CRP ( 83.5 vs. $24.5, \mathrm{p}<0.001) .{ }^{77}$

Obesity was shown to be associated with increased risk of $\mathrm{AF}$, due to its association with a chronic pro-inflammatory status and increased oxidative stress, both leading to onset and persistence of the supraventricular arrhyth- 
mia. ${ }^{78}$ Furthermore, an increased body mass index has also been linked to an increased volume of the left atrium that triggers the remodeling and inflammatory process, ultimately causing AF. ${ }^{79}$

Laboratory markers evaluated on presentation for AMI and their role in the development of new-onset $\mathrm{AF}$ were also analyzed by the TRIUMPH cohort, which found that both hs-CRP and BNP levels were correlated with the risk of arrhythmia. Surprisingly, troponin was not related to this risk. The study revealed that two times higher levels of NT pro-BNP associated an $18 \%$ increase in the rate of $\mathrm{AF}$ (OR 1.17, 95\% CI 1.02 to 1.34; $\mathrm{p}<0.02$ ) and a 2 -fold increase in hs-CRP levels led to a $15 \%$ higher frequency of the arrhythmia (OR 1.15, 95\% CI 1.02 to 1.30; p = 0.02), while no association was reported in relation to the increase of troponin (OR 0.94, 95\% CI 0.84 to $1.06, \mathrm{p}=0.3$ ). ${ }^{80}$ Other observations of the same study were that patients with $\mathrm{AF}$ were, as expected, older (mean age 64.6 \pm 13.2 years vs. $57.5 \pm 11.9$ years, $\mathrm{p}<0.001)$, Caucasian $(77.2 \%$ vs. $67.9 \%$, $\mathrm{p}$ $=0.021$ ), more likely to present diabetes ( $42.1 \%$ vs. $30.5 \%$ ), chronic renal failure ( $11.4 \%$ vs. $6.1 \%, \mathrm{p}=0.024)$, chronic pulmonary disorders ( $14 \%$ vs. $6.4 \%, p=0.002)$, or hypertension $(74.6 \%$ vs. $64.8 \%, p=0.033)$. Surprisingly, patients with $\mathrm{AF}$ were less likely to smoke compared to those in sinus rhythm $(24.8 \%$ vs. $43.6 \%, \mathrm{p}<0.001) .{ }^{80}$

The GUSTO 1 trial, which included 40,000 patients with AMI in the thrombolytic era, also found that the most important predictors for the development of $\mathrm{AF}$ are acute ventricular dysfunction at presentation (Killip I vs. Killip IV class: OR 3.28, 95\% CI 2.28 to 4.71) and older age (OR 3.2, 95\% CI 2.99 to 3.43). ${ }^{81}$ Data from the Osaka Acute Coronary Insufficiency trial revealed, once again, that patients with a higher risk of presenting AF presented more advanced Killip class IV (OR 2.06, 95\% CI 1.07 to 3.94), male gender (OR $1.89,95 \%$ CI 1.23 to 2.90 ), older age (OR 1.06, 95\% CI 1.04 to 1.07), and heart rate over $100 \mathrm{bpm}$ during admission (OR 3.0, $95 \%$ CI 1.94 to 4.64$).{ }^{82}$ Other studies found that females were more prone to develop arrhythmia, and other baseline characteristics that were commonly found in patients with $\mathrm{AF}$ and $\mathrm{AMI}$ were diabetes, hypertension, increased left atrial diameter, lower left ventricular ejection fraction, and impaired renal function. ${ }^{83-87}$

The type of reperfusion treatment applied for the AMI (thrombolysis or percutaneous revascularization) was not shown to significantly impact the risk of $\mathrm{AF}^{88}$ Furthermore, as shown by the RICO study on a cohort of 1,701 patients, there were no differences in the rate of new-onset $\mathrm{AF}$ in patients with ST-elevation and non-ST elevation AMI (7.6\% vs. $7.7 \%$ respectively, $\mathrm{p}=0.334) .{ }^{89}$ Another study showed no significant difference in the rate of $\mathrm{AF}$ in patients receiving fibrinolytic treatment (sinus rhythm $5.8 \%$ vs. $\mathrm{AF}-5.3 \%, \mathrm{p}=0.318$ ), but patients presenting this arrhythmia were more likely to benefit from in-hospital percutaneous revascularization (sinus rhythm - 29.7\% vs. AF $-46.5 \%, \mathrm{p}<0.001$ ), to have beta-blocker treatment upon hospital arrival (sinus rhythm $-13.1 \%$ vs. AF $21.9 \%, p=0.007$ ), as well as calcium channel blocker (sinus rhythm $-41.1 \%$ vs. AF $-50.9 \%, p=0.039$ ) compared to subjects in sinus rhythm, an observation which could indicate the pre-existing cardiac disorders. ${ }^{80}$ Kosmidou et al. (2018) performed a study on 1,812 patients with left main coronary atherosclerosis in sinus rhythm, out of which $162(8.9 \%)$ had developed AF after a mean period of $2.7 \pm$ 2.5 days of hospitalization. The arrhythmia was present in a significantly higher number of subjects that underwent coronary artery by-pass grafting (CABG) compared to those who benefited from percutaneous coronary revascularization of the left main ( $18 \%$ vs. $0.1 \%, p$ < 0.0001$).{ }^{90}$ Furthermore, the occurrence of AF in CABG patients was associated with subsequent death ( $11.4 \%$ vs. $4.3 \%$, adjusted HR 3.02, 95\% CI 1.60 to 5.70, p = 0.0006), stroke $(6.6 \%$ vs. $2.4 \%$, adjusted HR 4.19, 95\% CI 1.74 to $10.11, p=0.001$ ), and with the composite end-point of death, myocardial infarction, and stroke ( $22.6 \%$ vs. $12.8 \%$, adjusted HR 2.13 , $95 \%$ CI 1.39 to $3.25, \mathrm{p}=0.0004$ ) at the three-year followup.90 Other studies reported post-CABG AF frequency of $11-40 \%$ of patients. ${ }^{91-94}$ CABG is associated with an increased inflammatory response, which could explain the higher rate of arrhythmias compared to the minimally invasive percutaneous coronary revascularization.

\section{CONCLUSIONS}

AF developing in the context of an AMI can negatively and substantially impact patient outcomes during hospitalization as well as on the long term. Identification of patients at risk is of great significance, as it may lead to prompt therapeutic interventions and closer follow-up, thus improving prognosis and decreasing cardiovascular and cerebrovascular events that are linked to this comorbid association. Predictors for AF in AMI patients include advanced acute heart failures, higher Killip class on admission, increased admission heart rate, older age, female gender, previous cardiovascular disease, impaired renal function, diabetes, or low left ventricular ejection fraction. Laboratory parameters associated with an increased risk for AF include elevated levels of BNP and NT-proBNP, as well as hs-CRP, which are illustrative for the enhanced neurohormonal activation and the inflammatory response in the post-infarction period. 


\section{CONFLICT OF INTEREST}

Nothing to declare.

\section{ACKNOWLEDGEMENT}

The preparation and design of the present article is supported by the program of doctoral research of the University of Medicine and Pharmacy of Tîrgu Mureș, Romania, contract number 15241/29 from 21/10/2016.

\section{REFERENCES}

1. Chugh SS, Havmoeller R, Narayanan K, et al. Worldwide epidemiology of atrial fibrillation: a Global Burden of Disease 2010 Study. Circulation. 2014;129:837-847. doi: 10.1161/ CIRCULATIONAHA.113.005119.

2. Colilla S, Crow A, Petkun W, Singer DE, Simon T, Liu X. Estimates of current and future incidence and prevalence of atrial fibrillation in the U.S. adult population. Am J Cardiol. 2013;112:1142-1147. doi: 10.1016/j.amjcard.2013.05.063.

3. Ball J, Carrington MJ, McMurray JJ, Stewart S. Atrial fibrillation: profile and burden of an evolving epidemic in the 21st century. Int J Cardiol. 2013;167:1807-1824. doi: 10.1016/j. ijcard.2012.12.093.

4. Oldgren J, Healey JS, Ezekowitz $M$, et al. RE-LY Atrial Fibrillation Registry Investigators. Variations in cause and management of atrial fibrillation in a prospective registry of 15,400 emergency department patients in 46 countries: the RE-LY Atrial Fibrillation Registry. Circulation. 2014;129:15681576. doi: 10.1161/CIRCULATIONAHA.113.005451.

5. Ibanez B, James S, Agewall S, et al. 2017 ESC Guidelines for the management of acute myocardial infarction in patients presenting with ST-segment elevation. Eur Heart J. 2017;00:166. doi:10.1093/eurheartj/ehx393.

6. Wong CK, White HD, Wilcox RG, Criger DA, Califf RM, Topol EJ. New atrial fibrillation after acute myocardial infarction independently predicts death: the GUSTO-III experience. Am Heart J. 2000;140:878-885.

7. Romanov A, Martinek M, Pürerfellner $\mathrm{H}$, et al. Incidence of atrial fibrillation detected by continuous rhythm monitoring after acute myocardial infarction in patients with preserved left ventricular ejection fraction, results of the ARREST study. Europace. 2017;8:344. doi: 10.1093/europace/euw344.

8. Schmitt J, Duray G, Gersh BJ, Hohnloser SH. Atrial fibrillation in acute myocardial infarction: a systematic review of the incidence, clinical features and prognostic implications. Eur Heart J. 2009;39:1038-1045. doi: 10.1093/eurheartj/ehn579.

9. Rathore SS, Berger AK, Weinfurt KP, Schulman KA, Oetgen WJ, Gersh BJ. Acute myocardial infarction complicated by atrial fibrillation in the elderly: prevalence and outcomes. Circulation. 2000;101:969-974.

10. Kea B, Alligood T, Manning V, Raitt M. A Review of the Relationship of Atrial Fibrillation and Acute Coronary Syndrome. Current emergency and hospital medicine reports. 2016;4:107-118. doi: 10.1007/s40138-016-0105-2.

11. McManus DD, Huang W, Domakonda KV, et al. Trends in Atrial Fibrillation in Patients Hospitalized with an Acute Coronary
Syndrome. The American Journal of Medicine. 2012;125:10761084. doi: 10.1016/j.amjmed.2012.05.024.

12. Angeli F, Reboldi G, Garofoli $M$, et al. Atrial fibrillation and mortality in patients with acute myocardial infarction: a systematic overview and meta-analysis. Curr Cardiol Rep. 2012;14:601-610. doi: 10.1007/s11886-012-0289-3.

13. Jabre P, Roger VL, Murad MH, et al. Mortality associated with atrial fibrillation in patients with myocardial infarction: a systematic review and metaanalysis. Circulation. 2011;123:1587-1593. doi: 10.1161/ CIRCULATIONAHA.110.986661.

14. January CT, Wann LS, Alpert JS, et al. 2014 AHA/ACC/ HRS guideline for the management of patients with atrial fibrillation: a report of the American College of Cardiology/ American Heart Association Task Force on Practice Guidelines and the Heart Rhythm Society. J Am Coll Cardiol. 2014;64:e176.

15. Mozaffarian D, Benjamin EJ, Go AS, et al. Heart Disease and Stroke Statistics-2016 Update: A Report From the American Heart Association. Circulation. 2016;133:e38-e360. doi: 10.1161/cir.0000000000000350.

16. Ghushchyan V, Nair KV, Page RL 2nd. Indirect and direct costs of acute coronary syndromes with comorbid atrial fibrillation, heart failure, or both. Vasc Health Risk Manag. 2015;11:25-34. doi: 10.2147/VHRM.S72331.

17. Lau DH, Alasady M, Brooks AG, Sanders P. New-onset atrial fibrillation and acute coronary syndrome. Expert Rev Cardiovasc Ther. 2010;8:941-948. doi: 10.1586/erc.10.61.

18. Rubenstein JC, Cinquegrani MP, Wright J. Atrial Fibrillation in Acute Coronary Syndrome. Journal of Atrial Fibrillation. 2012;5:551. doi: 10.4022/jAF.551.

19. AnneW, Willems R, Roskams T, et al.Matrix metalloproteinases and atrial remodeling in patients with mitral valve disease and atrial fibrillation. Cardiovasc Res. 2005;67:655-666. doi: 10.1016/j.cardiores.2005.04.016.

20. Nguyen BL, Fishbein MC, Chen LS, Chen PS, Masroor S. Histopathological substrate for chronic atrial fibrillation in humans. Heart Rhythm. 2009;6:454-460. doi: 10.1016/j. hrthm.2009.01.010.

21. Spach MS, Josephson ME. Initiating reentry: the role of non-uniform anisotropy in small circuits. J Cardiovasc Electrophysiol. 1994;5:182-209.

22. Greiser M. Calcium signalling silencing in atrial fibrillation. J Physiol. 2017;595:4009-4017. doi: 10.1113/JP273045.

23. Kirchhof P, Benussi S, Kotecha D, et al. 2016 ESC Guidelines for the management of atrial fibrillation developed in collaboration with EACTS. Eur J Cardiothorac Surg. 2016;50:e1e88. doi: 10.1093/ejcts/ezw313.

24. Jalife J, Kaur K. Atrial Remodeling, Fibrosis and Atrial Fibrillation. Trends in cardiovascular medicine. 2015;25:475484. doi: 10.1016/j.tcm.2014.12.015.

25. Kotecha D, Piccini JP. Atrial fibrillation in heart failure: what should we do? Eur Heart J. 2015;36:3250-3257. doi: 10.1093/ eurheartj/ehv513.

26. Alasady M, Lau D, Brooks A, et al. Atrial ischemia rather than neurohormonal or hemodynamic changes associᄀated with acute myocardial infarction results in substrate for atrial fibrillation. Heart, Lung and Circulation. 2010;19:S2. doi: 10.1016/j.hlc.2010.06.668

27. Alasady M, Abhayaratna WP, Leong DP, et al. Coronary artery disease affecting the atrial branches is an independent 
determinant of atrial fibrillation after myocardial infarction. Heart Rhythm. 2011;8:955-960. doi: 10.1016/j. hrthm.2011.02.016.

28. Ferreira JP, Santos M. Heart failure and atrial fibrillation: from basic science to clinical practice. Int J Mol Sci. 2015;16:31333147. doi: 10.3390/ijms16023133.

29. McMurray JJ, Adamopoulos S, Anker SD, et al. ESC Guidelines for the diagnosis and treatment of acute and chronic heart failure 2012: The Task Force for the Diagnosis and Treatment of Acute and Chronic Heart Failure 2012 of the European Society of Cardiology. Developed in collaboration with the Heart Failure Association (HFA) of the ESC. Eur Heart J. 2012;33:1787-1847. doi: 10.1093/eurheartj/ehs104.

30. Kober L, Swedberg K, McMurray JJ, et al. Previously known and newly diagnosed atrial fibrillation: a major risk indicator after a myocardial infarction complicated by heart failure or left ventricular dysfunction. Eur J Heart Fail. 2006;8:591-598. doi: 10.1016/j.ejheart.2005.11.007.

31. Kochiadakis GE, Skalidis EI, Kalebubas MD, et al. Effect of acute atrial fibrillation on phasic coronary blood flow pattern and flow reserve in humans. Eur Heart J. 2002;23:734-741. doi: 10.1053/euhj.2001.2894.

32. Ariyarajah V, Malinski M, Khadem A, et al. Relation of recurrence of atrial fibrillation after non-ST-elevation acute myocardial infarction to left atrial abnormality. Am J Cardiol. 2008;101:30-34. doi: 10.1016/j.amjcard.2007.07.044.

33. Cha YM, Redfield MM, Shen WK, Gersh BJ. Atrial fibrillation and ventricular dysfunction: A vicious electromechanical cycle. Circulation. 2004;109:2839-2843. doi: 10.1161/01. CIR.0000132470.78896.A8.

34. De Jong AM, Maass AH, Oberdorf-Maass SU, et al. Mechanisms of atrial structural changes caused by stretch occurring before and during early atrial fibrillation. Cardiovasc Res. 2011;89:754-765. doi: 10.1093/cvr/cvq357.

35. Guo Y, Lip GY, Apostolakis S. Inflammation in atrial fibrillation. J Am Coll Cardiol. 2012;60:2263-2270. doi: 10.1016/j.jacc.2012.04.063.

36. Liuba L, Ahlomroth H, Jonasson L, et al. Source of inflammatory markers in patients with atrial fibrillation. Europace. 2008;10:848-53. doi: 10.1093/europace/eun111.

37. Li J, Solus J, Chen Q et al. Role of inflammation and oxidative stress in atrial fibrillation. Heart Rhythm. 2010;7:438-444. doi: 10.1016/j.hrthm.2009.12.009.

38. Pan $\mathrm{M}$, Zhu JH, Jiang WP, et al. Inflammation: a possible pathogenic link to atrial fibrillation. Med Hypotheses. 2006;67:1305-1307. doi: 10.1016/j.mehy.2006.05.034.

39. Aronson D, Boulos M, Suleiman A, et al. Relation of C-reactive protein and new-onset atrial fibrillation in patients with acute myocardial infarction. Am J Cardiol. 2007;100:753-757. doi: 10.1016/j.amjcard.2007.04.014.

40. Hwang HJ, Ha JW, Joung B, et al. Relation of inflammation and left atrial remodeling in atrial fibrillation occurring in early phase of acute myocardial infarction. Int J Cardiol. doi: 10.1016/j. ijcard.2009.05.065.

41. Ma CY, Xu ZY, Wang SP, et al. Change of Inflammatory Factors in Patients with Acute Coronary Syndrome. Chinese Medical Journal. 2018;131:1444-1449. doi: 10.4103/0366-6999.233953.

42. Meuwissen M, van der Wal AC, Siebes M, et al. Role of plaque inflammation in acute and recurrent coronary syndromes. Netherlands Heart Journal. 2004;12:106-109.

43. Centurion OA. Serum biomarkers and source of inflammation in acute coronary syndromes and percutaneous coronary interventions. Cardiovasc Revasc Med. 2016;17:119-128. doi: 10.1016/j.carrev.2016.01.005.

44. Fang L, Moore XL, Dart AM, Wang LM. Systemic inflammatory response following acute myocardial infarction. Journal of Geriatric Cardiology: JGC. 2015;12:305-312. doi: 10.11909/j. issn.1671-5411.2015.03.020.

45. Frangogiannis NG. The inflammatory response in myocardial injury, repair and remodeling. Nature Reviews Cardiology. 2014;11:255-265. doi: 10.1038/nrcardio.2014.28.

46. Sukhija R, Fahdi I, Garza L, et al. Inflammatory markers, angiographic severity of coronary artery disease, and patient outcome. Am J Cardiol. 2007;99:879-884. doi: 10.1016/j. amjcard.2006.11.032.

47. Frangogiannis NG. Regulation of the inflammatory response in cardiac repair. Circulation Research. 2012;110:159-273. doi: 10.1161/CIRCRESAHA.111.243162.

48. Seropian IM, Toldo S, Van Tassell BW, Abbate A. Antiinflammatory strategies for ventricular remodeling following ST-segment elevation acute myocardial infarction. J Am Coll Cardiol. 2014;63:1593-1603. doi: 10.1016/j.jacc.2014.01.014.

49. Westman PC1, Lipinski MJ1, Luger D, et al. Inflammation as a Driver of Adverse Left Ventricular Remodeling After Acute Myocardial Infarction. J Am Coll Cardiol. 2016;67:2050-2060. doi: 10.1016/j.jacc.2016.01.073.

50. De Servi S, Mariani M, Mariani G, Mazzone A. C-reactive protein increase in unstable coronary disease cause or effect? J Am Coll Cardiol. 2005;46:1496-1502. doi: 10.1016/j. jacc.2005.05.083.

51. Li JJ, Fang CH. C-reactive protein is not only an inflammatory marker but also a direct cause of cardiovascular diseases. Med Hypotheses. 2004;62:499-506. doi: 10.1016/j. mehy.2003.12.014.

52. van der Meer IM, de Maat MP, Kiliaan AJ, van der Kuip DA, Hofman A, Witteman JC. The value of C-reactive protein in cardiovascular risk prediction: the Rotterdam Study. Arch Intern Med. 2003;163:1323-1328. doi: 10.1001/ archinte.163.11.1323.

53. Sheikh AS, Yahya S, Sheikh NS, et al. C-reactive protein as a predictor of adverse outcome in patients with acute coronary syndrome. Heart Views. 2012;13:7-12. doi: 10.4103/1995705X.96660.

54. Valgimigli M, Ceconi C, Malagutti P, et al. Tumor necrosis factor-alpha receptor 1 is a major predictor of mortality and new-onset heart failure in patients with acute myocardial infarction: the cytokine-activation and long-term prognosis in myocardial infarction (C-ALPHA) study. Circulation. 2005;111:863-870. doi: 10.1161/01.CIR.0000155614.35441.69.

55. Andrie RP, Becher UM, Frommold R, et al. Interleukin-6 is the strongest predictor of 30-day mortality in patients with cardiogenic shock due to myocardial infarction. Crit Care. 2012;16:R152.

56. Dayawansa NH, Gao XM, White DA, et al. Role of MIF in myocardial ischaemia and infarction: insight from recent clinical and experimental findings. Clin Sci. 2014;127:149-161. doi: 10.1042/CS20130828.

57. Engelmann MD, Svendsen JH. Inflammation in the genesis and perpetuation of atrial fibrillation. Eur Heart J. 2005;26:20832092. doi: 10.1093/eurheartj/ehi350.

58. Boos CJ, Anderson RA, Lip GY. Is atrial fibrillation an inflammatory disorder? Eur Heart J. 2006;27:136-149. doi: 10.1093/eurheartj/ehi645.

59. Patel P, Dokainish H, Tsai P, Lakkis N. Update on the 
association of inflammation and atrial fibrillation. J Cardiovasc Electrophysiol. 2010;21:1064-1070. doi: 10.1111/j.15408167.2010.01774.x.

60. Frustaci A, Chimenti C, Bellocci F, Morgante E, Russo MA, Maseri A. Histological substrate of atrial biopsies in patients with lone atrial fibrillation. Circulation. 1997;96:1180-1184.

61. Aviles RJ, Martin DO, Apperson-Hansen C, et al. Inflammation as a risk factor for atrial fibrillation. Circulation. 2003;108:3006-3010. doi: 10.1161/01.CIR.0000103131.70301.4F.

62. Chung MK, Martin DO, Sprecher D, et al. C-reactive protein elevation in patients with atrial arrhythmias: Inflammatory mechanisms and persistence of atrial fibrillation. Circulation. 2001;104:2886-2891.

63. Kallergis EM, Manios EG, Kanoupakis EM, et al. The role of the post-cardioversion time course of hs-CRP levels in clarifying the relationship between inflammation and persistence of atrial fibrillation. Heart. 2008;94:200-204. doi: 10.1136/ hrt.2006.108688.

64. Marcus GM, Whooley MA, Glidden DV, Pawlikowska L, Zaroff JG, Olgin JE. Interleukin-6 and atrial fibrillation in patients with coronary artery disease: data from the Heart and Soul Study. Am Heart J. 2008;155:303-309. doi: 10.1016/j. ahj.2007.09.006.

65. Floria M, Barboi O, Rezus C, et al. Atrial Fibrillation and Gastro-Oesophageal Reflux Disease - Controversies and Challenges. Curr Pharm. 2015;21:3829-3834.

66. Issac TT, Dokainish H, Lakkis NM. Role of inflammation in initiation and perpetuation of atrial fibrillation: a systematic review of the published data. J Am Coll Cardiol. 2007;50:20212028. doi: 10.1016/j.jacc.2007.06.054.

67. Pellegrino PL, Brunetti ND, Gennaro LD, Ziccardi L, Grimaldi $\mathrm{M}$, Biase $\mathrm{MD}$. Inflammatory activation in an unselected population of subjects with atrial fibrillation: links with structural heart disease, atrial remodeling and recent onset. Intern Emerg Med. 2011;8:123-128. doi: 10.1007/s11739-0110557-z.

68. Marcus GM, Smith L, Ordovas K, et al. Intracardiac and extracardiac markers of inflammation during atrial fibrillation. Heart Rhythm. 2010;7:149-154. doi: 10.1016/j. hrthm.2009.10.004.

69. Conway DS, Buggins P, Hughes E, Lip GY. Prognostic significance of raised plasma levels of interleukin-6 and C-reactive protein in atrial fibrillation. Am Heart J. 2004;148:462-466. doi: 10.1016/j.ahj.2004.01.026.

70. Conway DS, Buggins P, Hughes E, Lip GY. Relation of interleukin-6, C-reactive protein, and the prothrombotic state to transesophageal echocardiographic findings in atrial fibrillation. Am J Cardiol. 2004;93:1368-1373. doi: 10.1016/j. amjcard.2004.02.032.

71. Aronson D, Boulos M, Suleiman A, et al. Relation of C-reactive protein and new-onset atrial fibrillation in patients with acute myocardial infarction. Am J Cardiol. 2007;100:753-757. doi: 10.1016/j.amjcard.2007.04.014.

72. Hwang HJ, Ha JW, Joung B, et al. Relation of inflammation and left atrial remodeling in atrial fibrillation occurring in early phase of acute myocardial infarction. Int J Cardiol. 2011;146:28-31. doi: 10.1016/j.ijcard.2009.05.065.

73. Ren Y, Zeng RX, Li JJ, et al. Relation of C-reactive protein and new-onset atrial fibrillation in patients with acute myocardial infarction: A systematic review and meta-analysis. Int J Cardiol. 2015;190:268-70. doi: 10.1016/j.ijcard.2015.04.152.
74. Clark DM, Plumb VJ, Epstein AE, Kay GN. Hemodynamic effects of an irregular sequence of ventricular cycle lengths during atrial fibrillation. J Am Coll Cardiol. 1997;30:1039-1045.

75. Roy D, Brugada P, Wellens HJ. Atrial tachycardia facilitating initiation of ventricular tachycardia. Pacing Clin Electrophysiol. 1983;6:47-52.

76. Gronefeld GC, Mauss O, Li YG, Klingenheben T, Hohnloser $\mathrm{SH}$. Association between atrial fibrillation and appropriate implantable cardioverter defibrillator therapy: results from a prospective study. J Cardiovasc Electrophysiol. 2000;11:120814.

77. Vukmirović M, Bošković A, Tomašević Vukmirović I, et al. Predictions and Outcomes of Atrial Fibrillation in the Patients with Acute Myocardial Infarction. Open Medicine. 2017;12:115124. doi: 10.1515/med-2017-0018.

78. Munger TM, Dong YX, Masaki M, et al. Electrophysiological and hemodynamic characteristics associated with obesity in patients with atrial fibrillation. J Am Coll Cardiol. 2012;60:851860. doi: 10.1016/j.jacc.2012.03.042.

79. Dernellis J, Panaretou M. C-reactive protein and paroxysmal atrial fibrillation, evidence of the implication of an inflammatory process in paroxysmal atrial fibrillation. Acta Cardiol. 2001;56:375-380.

80. Parashar S, et al. New-onset atrial fibrillation after acute myocardial infarction and its relation to admission biomarkers (from the TRIUMPH registry). Am J Cardiol. 2013;112:13901395 .

81. Crenshaw BS, Ward SR, Granger CB, Stebbins AL, Topol EJ, Califf RM. Atrial fibrillation in the setting of acute myocardial infarction: the GUSTO-I experience. Global Utilization of Streptokinase and TPA for Occluded Coronary Arteries. J Am Coll Cardiol. 1997;30:406-413.

82. Kinjo K, Sato H, Sato H, Ohnishi Y, Hishida E, Nakatani D. Prognostic significance of atrial fibrillation/atrial flutter in patients with acute myocardial infarction treated with percutaneous coronary intervention. Am J Cardiol. 2003; 92:1150-1154.

83. Park MJ, Jung JI, Oh YS, Youn HJ. Assessment of the structural remodeling of the left atrium by 64 -multislice cardiac CT: comparative studies in controls and patients with atrial fibrillation. Int J Cardiol. 2012;159:181-186. doi: 10.1016/j. ijcard.2011.02.053.

84. Jabre P, Jouven X, Adnet F, et al. Atrial fibrillation and death after myocardial infarction: a community study. Circulation. 2011;123:2094-2100. doi: 10.1161/ CIRCULATIONAHA.110.990192.

85. Podolecki T, Lenarczyk R, Kowalczyk J, et al. Effect of type of atrial fibrillation on prognosis in acute myocardial infarction treated invasively. Am J Cardiol. 2012;109:1689-1693. doi: 10.1016/j.amjcard.2012.02.009.

86. Rene AG, Généreux P, Ezekowitz M, et al. Impact of atrial fibrillation in patients with ST-elevation myocardial infarction treated with percutaneous coronary intervention (from the HORIZONS-AMI [Harmonizing Outcomes With Revascularization and Stents in Acute Myocardial Infarction] trial). Am J Cardiol. 2014;113:236-242.

87. Guenancia C, Stamboul K, Garnier F, et al. Obesity and newonset atrial fibrillation in acute myocardial infarction: a gender specific risk factor. Int J Cardiol. 2014;176:1039-1041. doi: 10.1016/j.ijcard.2014.07.291.

88. Siu CW, Jim MH, Ho HH, Miu R, Lee SW, Lau CP. Transient 
atrial fibrillation complicating acute inferior myocardial infarction: implications for future risk of ischemic stroke. Chest. 2007;132:44-49. doi: 10.1378/chest.06-2733.

89. Laurent G, Dentan G, Moreau D, Zeller M, Laurent Y, VincentMartin M. Atrial fibrillation during myocardial infarction with and without ST segment elevation. Arch Mal Coeur Vaiss. 2005; 98:608-614.

90. Kosmidou I, Chen S, Kappetein AP, et al. New-Onset Atrial Fibrillation After PCI or CABG for Left Main Disease: The EXCEL Trial. J Am Coll Cardiol. 2018;71:739-748. doi: 10.1016/j. jacc.2017.12.012.

91. Echahidi N, Pibarot P, O'Hara G, Mathieu P. Mechanisms, prevention, and treatment of atrial fibrillation after cardiac surgery. J Am Coll Cardiol. 2008;51:793-801. doi: 10.1016/j. jacc.2007.10.043.

92. Chelazzi C, Villa G, De Gaudio AR. Postoperative Atrial Fibrillation. ISRN Cardiology. 2011;2011:203179. doi:10.5402/2011/203179.

93. Alawami M, Chatfield A, Ghashi R, Walker L. Atrial fibrillation after cardiac surgery: Prevention and management: The Australasian experience. Journal of the Saudi Heart Association. 2018;30:40-46. doi: 10.1016/j.jsha.2017.03.008.

94. Alqahtani AAR. Atrial Fibrillation Post Cardiac Surgery Trends Toward Management. Heart Views : The Official Journal of the Gulf Heart Association. 2010;11:57-63. doi: 10.4103/1995705X.73212. 